\title{
Dossiê Aborto
}

\section{APRESENTAÇÃO}

\author{
CARMEN SUSANA TORNQUIST \\ Universidade do Estado de Santa Catarina \\ CRISTIANI BERETA DA SILVA \\ Universidade do Estado de Santa Catarina
}

MARA COELHO DE SOUZA LAGO

Universidade Federal de Santa Catarina

Uma revista que trabalha com a temática de gênero a partir da perspectiva feminista não poderia deixar de refletir mais uma vez sobre o aborto, sobretudo num contexto em que se reacende esse debate, tanto no Brasil como em vários outros países onde, até hoje, tal polêmica não se resolveu.

Para contribuir com a ruptura do sonoro silêncio' sobre essa prática, a editoria de dossiês da REF decidiu organizar esta seção, cujo nome replica o Dossiê Aborto de 1997. Foram retomadas discussões sobre os direitos sexuais e reprodutivos ocorridas na década de 90 que, de forma tímida, como sugere Leila Linhares Barsted (1997), ${ }^{2}$ vêm legitimando internacionalmente o debate feminista acerca do direito das mulheres de decidirem sobre seus corpos e optarem pela maternidade. Aliás, é também Leila Barsted que discute no primeiro número da REF de $1992,{ }^{3}$ de forma provocativa, a luta pelo "aborto legal" como estratégia do feminismo brasileiro, que, segundo ela, não deveria perder seu rumo abandonando a luta pela descriminalização do aborto em qualquer situação. Esse direito seria, como afirma Michèle Ferrand no presente dossiê, uma condição para a emancipação feminina, cabendo às mulheres a decisão final sobre processos que afetam não somente seus corpos, mas também suas vidas.

Vários outros textos sobre o tema têm sido publicados ao longo dos 15 anos da REF, direta ou indiretamente, seja na forma de artigos, seja na forma de entrevistas e/ou resenhas, com destaque para os dossiês "Mulher e direitos reprodutivos" ${ }^{4}$ e, ainda, "Relações de gênero" e "Saúde reprodutiva". 5

\footnotetext{
${ }^{1}$ Expressão de Flávia MOTTA, 2008. Ver neste dossiê.

2 Leila Linhares BARSTED, v. 5, n. 2, 1997.

${ }^{3}$ BARSTED, v. 0, n. 1, 1992.

${ }^{4}$ REVISTA ESTUDOS FEMINISTAS, Rio de Janeiro, CIEC/UERJ, v. 1, n. 2, 1993.

${ }^{5}$ REVISTA ESTUDOS FEMINISTAS, Florianópolis, CFH/CCE/UFSC, v. 8, n. 1, 2000.
} 
Na atualidade, porém, há um contexto diverso daquele dos anos 80 e 90: de um lado, a visita do Papa Bento XVI ao Brasil, em maio de 2007, mais uma vez reacende a mobilização dos grupos pró-vida, que contam não só com o apoio de grande parte dos meios de comunicação, como também com a força daquilo que Leila Linhares chamou, tão acertadamente, de "rede nacional de púlpitos";' de outro lado, destacamos uma nova conjuntura política na América Latina, com a ascensão de governos mais abertos aos movimentos de mulheres e às questões de saúde pública, na qual a questão do aborto é recolocada na agenda política, como nos casos do Uruguai, da Argentina, do Chile, da Bolívia e do Brasil. No Brasil, mais especificamente, há que se destacar a postura propositiva do governo federal, que, por meio do Ministério da Saúde e da Secretaria Especial de Políticas para as Mulheres, permitiu que feministas e setores progressistas do direito e da saúde compusessem a Comissão Tripartite, que tem por base as deliberações da Conferência Nacional de Mulheres, em 2005, como forma de analisar a questão.

Não é só isto. O Congresso Nacional continua sendo o receptáculo de inúmeros projetos de lei acerca do tema, como o do deputado evangélico e petista Henrique Afonso, que propõe o pagamento de uma bolsa-auxílio para as mães vítimas de violência sexual para que assumam os filhos e declinem do direito ao aborto legalmente permitido, que foi muito apropriadamente apelidado de bolsa-estupro por feministas do Cfemea. Mais recentemente, em junho de 2008, um juiz do Mato Grosso do Sul também decidiu entrar na discussão e incriminar cerca de pelo menos 26 mulheres que haviam cometido o "crime do aborto", penalizando-as com trabalhos comunitários realizados em creches como forma de "educá-las" para a maternidade e culpabilizá-las.

Além disso, temos como um marco no Brasil a polêmica instaurada em 2004, quando foi concedida liminar por ministro do Supremo Tribunal Federal, que, atendendo à demanda feita por feministas, garantia a inclusão nos casos de aborto legal previstos pelo Código Penal de 1940 (risco de vida da mãe e estupro) dos casos de comprovação de anencefalia. A liminar autorizando a interrupção da gravidez por má-formação fetal (anencefalia) foi cassada logo a seguir, numa clara demonstração da enorme fragilidade da República brasileira. Até mesmo em casos em que a chamada vida do feto, eixo dos discursos morais religiosos, não poderia se efetivar, as mulheres estão impedidas de interromper a gravidez.

Em recente mapeamento sobre a legislação concernente ao aborto no cenário mundial, o Brasil, ao lado de mais 67 países, aparece como parte do bloco das nações que adotam as leis mais duras em relação ao aborto. Já o Uruguai e a Argentina, ao lado de mais 33 países, partilham do conjunto de nações que permitem o aborto em situações específicas para preservar a saúde física da mulher. França e Portugal fazem parte do conjunto de países cuja legislação permite, de forma mais ampla, a realização do aborto. ${ }^{7}$ Muito embora tenhamos que ter claro que, no caso de Portugal, ${ }^{8} \mathrm{O}$ instituto da "objeção de consciência", por parte dos profissionais dos serviços públicos, não deixa de ser um modo velado de, na prática, dificultar a interrupção da gravidez pela mulher. Da mesma forma, a necessidade de um aval médico para legitimar o chamado "sofrimento psíquico da mulher" (no caso da França) aponta para os limites da noção de "aborto legal".

Chamamos atenção para o fato de que a França assim como o Uruguai são países natalistas, ao contrário do Brasil, onde a temática sempre aparece articulada às supostas

\footnotetext{
${ }^{6}$ BARSTED, 1992, p. 106.

${ }^{7}$ Ver mapa feito pelo Center for Reproductive Rights (Centro de Direitos Reprodutivos), ONG com sede em Nova York, ao pesquisar as leis em 196 países e Estados independentes (CENTER FOR REPRODUCTIVE RIGHTS, 2007).

${ }^{8}$ Ver artigo de Rozeli PORTO, 2008. Ver neste dossiê.
} 
necessidades de controle do crescimento demográfico. No caso da França, o debate acerca do aborto aparece mais diretamente ligado à polêmica sobre o direito à contracepção e à vivência da sexualidade de uma forma prazerosa e livre, como sublinha Michèle Ferrand em seu artigo neste dossiê. Cabe destacar que a legislação francesa atinente ao aborto, que permite a Interrupção Voluntária da Gravidez (IVG) em situações de sofrimento psíquico da mulher, embora pareça muito menos restritiva do que a dos países hispânicos, por exemplo, concede aos especialistas a última palavra acerca da decisão que, para as feministas, caberia às mulheres, como mostra Danièlle Ardaillon. ${ }^{9}$ Essa é uma questão que repousa numa larga história de medicalização dos corpos das mulheres e da saúde feminina. Embora apresentem realidades bastante distintas, os debates sobre 0 aborto realizados no Brasil, no Uruguai, em Portugal e na França produzem e fazem circular discursos historicamente ligados às relações sociais e de poder que implicam disputas de controle sobre os corpos e a sexualidade das mulheres.

Os artigos deste dossiê trazem análises que repousam em metodologias e referências teóricas diversas, porém, todos apontam para a permanência (ou o reforço) das tensões e das complexidades que envolvem o tema, desde o domínio daquilo que nós chamamos de "intimidade" até o campo da macropolítica, já que aborto, gravidez e concepção são alvos do biopoder. Como esclarece Susana Rostagnol em seu artigo:

[...] el aborto es bastante más que un asunto de mujeres, aunque es principalmente un asunto de mujeres que acontece en el cuerpo de una determinada mujer. El aborto forma parte de la gran política, de las formas en que las sociedades se dan para organizar la convivência y para construir las relaciones sociales, especialmente las relaciones de gênero. ${ }^{10}$

Os artigos que se seguem refletem sobre as histórias das articulações entre movimentos e aspirações feministas e a construção das leis que regulamentam a contracepção em diferentes países, detendo-se também nas formas com que as pessoas (profissionais de saúde e/ou mulheres) vivenciam essas situações.

Em nome da vida, ou melhor, em defesa da vida, muitos e longos debates vêm sendo travados nas últimas décadas, em diferentes países. O lançamento da Campanha da Fraternidade da Igreja Católica sob o título $A$ defesa da vida, em 2008, recrudesce essa discussão no cenário brasileiro e polariza posições e argumentos entre diferentes grupos e lugares em que se entrecruzam discursos: religiosos, legislativos, jurídicos, médicos, movimentos feministas, dentre outros. É interessante observar como os discursos pró-vida da campanha católica (chamada por feministas brasileiras de "campanha da fatalidade") recorrem mais, neste momento, a argumentos biologizantes do que aos tradicionais argumentos religiosos acerca da existência da alma.

O artigo "Vozes católicas no Congresso Nacional: aborto, defesa da vida", assinado por Myriam Aldana, retoma parte dos debates em "defesa da vida" travados no Congresso Nacional em torno da proposta da Emenda Constitucional PEC25/95, de autoria do deputado Severino Cavalcanti (PPB/PE), que pretendia mudar a redação do artigo $5^{\circ} \mathrm{da}$ Constituição Federal, acrescentando ao "direito à vida" a expressão "desde a concepção". A autora analisa posições e contradições nos discursos da lgreja Católica e do movimento feminista, bem como as inscrições desses discursos e contradiscursos como "verdadeiros". As questões discutidas neste artigo revelam-se bastante atuais e convidam leitores e leitoras

${ }^{9}$ Danièlle ARDAILLON, v. 5, n. 2, 1997.

10 Susana ROSTAGNOL, 2008. Ver neste dossiê. 
a refletir sobre as posições assumidas em "defesa da vida" no debate recente sobre o aborto no Brasil.

Como mencionamos anteriormente, em julho de 2004, o então ministro do Supremo Tribunal Federal Marco Aurélio de Mello concedeu liminar que autorizava mulheres a interromper a gestação em caso de anencefalia fetal. Essa decisão (revogada no Plenário do Supremo Tribunal Federal em outubro do mesmo ano) instaurou acirrados debates e combates sobre o aborto no Brasil. Os discursos jurídicos e políticos que circularam nessa ocasião são alvo - como um "fio de Ariadne" - das análises da antropóloga Débora Diniz e da médica Ana Cristina Vélez no artigo "Aborto na Suprema Corte: o caso da anencefalia no Brasil". As autoras observaram que os argumentos utilizados no Supremo e que cassaram a liminar da anencefalia sofreram deslocamentos do campo da razão pública para o campo dos argumentos religiosos. Esse deslocamento e suas implicações demonstram que o debate sobre o aborto no Brasil coloca sob suspeição os fundamentos constitucionais da laicidade do Estado e expõem a fragilidade da razão pública em temas de direitos reprodutivos.

Débora Diniz é autora de dois importantes filmes sobre os casos de aborto "legais", um sobre anencefalia" e outro sobre os casos de gravidez decorrente de estupro, ${ }^{12}$ tragédias que estraçalham vidas de mulheres e de crianças, já que, apesar de serem garantidos por lei, diante de uma violação seguida de concepção, são poucos os profissionais de saúde e agentes do Direito que efetivamente se empenham em garantir o direito dessas mulheres em deter a gravidez (em que pesem os louváveis esforços que vêm sendo feitos no Brasil pelas feministas e pelos profissionais de saúde efetivamente engajados na Reforma Sanitária para a reversão desse quadro).

Michèle Ferrand, socióloga francesa, relata sua trajetória de militante dos movimentos feministas na França e de pesquisadora voltada para as questões de contracepção e direitos reprodutivos. Ela apresenta um panorama das lutas feministas a favor do controle do próprio corpo e da sexualidade pelas mulheres. Em seu artigo, em tom de testemunho, Michèle deixa claras as relações entre sua produção acadêmica sobre o tema e suas posições políticas e experiências de vida, delineando um histórico das articulações políticas, jurídicas e de movimentos feministas na elaboração/implementação das leis que regem as questões do aborto em seu país. A autora nos fornece um conjunto de referências bibliográficas que decidimos manter no texto, dada a importância que a produção feminista francófona tem no cenário dos estudos de gênero, assim como indica a importância dessa discussão no contexto francês. Ao mesmo tempo, destaca-se o fato assinalado pela autora de que, também na França, antes da aprovação do aborto legal, as mulheres com mais recursos econômicos tinham opções de realizar aborto com maior segurança em clínicas clandestinas ou fora do país, ao contrário das mulheres das camadas populares, que, como na maioria dos países pobres, eram forçadas a recorrer a métodos precários e inseguros e arriscavam suas próprias vidas.

Rozeli Porto, doutoranda em Antropologia Social, realizou estudos em Portugal justamente no momento posterior ao referendo de 11 de fevereiro de 2007, que descriminalizou o aborto nesse país. Ela entrevistou profissionais da área médica e colheu depoimentos de enfermeiras e médicas/os sobre a experiência recente de Interrupção Voluntária da Gravidez (IVG) nos hospitais públicos do país. As entrevistas com as/os profissionais de saúde revelaram aspectos sobre a alegação do "impedimento de

\footnotetext{
${ }^{11}$ HISTÓRIA..., 2005.

${ }^{12}$ A MARGEM..., 2004.
} 
consciência", utilizada por alguns como recusa de participar nos procedimentos de interrupção da gravidez, e alertaram para o tratamento discriminatório e, às vezes, humilhante dado às mulheres que realizam aborto. Algumas falas das/os entrevistadas/os questionam o uso do "impedimento de consciência" por médicos que se recusam a interromper a gravidez até 10 semanas por livre opção das mulheres. A autora analisa essa recusa como uma impossibilidade desses profissionais de aceitarem que a mulher possa ter todo esse poder em relação ao seu próprio corpo (e vida), escapando da tutela dos homens e dos médicos. Chamamos atenção para os dados de sua pesquisa que sugerem que a "objeção de consciência" interpela a própria legitimidade da nova lei e recoloca, no plano privado e moral, questões que deveriam situar-se no plano da razão pública, como sustentam Débora Diniz e Ana Velez em seu artigo.

A antropóloga Susana Rostagnol conta um pouco da história do movimento pela legalização do aborto no Uruguai em seu artigo "El conflicto mujer-embrión em debate parlamentario sobre el aborto", em que analisa as discussões realizadas no seu país entre outubro e novembro de 2007, período da votação do projeto de lei de legalização do aborto no país. Os elementos envolvidos e subjacentes aos conflitos mulher/embrião, controle patrimonial do corpo e autonomia são as questões centrais sobre as quais Susana se debruça com cuidado e atenção, por meio do embate que acompanhou no Senado Nacional e no qual circularam muitos dos discursos que aparecem também nos outros países. O movimento pela legalização do aborto nesse país é parte de um processo histórico que expõe a complexidade e os limites das lutas e das disputas em torno das questões que envolvem a saúde sexual e reprodutiva das mulheres sul-americanas. Na história recente do Uruguai, projetos de legalização ou despenalização do aborto vêm sendo colocados em pauta, discutidos, debatidos, aprovados, vetados, enfim, movimentos que informam os avanços e os recuos dessas lutas.

O artigo de Lucila Scavone analisa os debates e as ações do movimento feminista brasileiro pela liberação do aborto em relação à alteração da legislação do País sobre contracepção. A autora acompanha a trajetória recente do movimento feminista no Brasil, em suas estratégias para avançar nas conquistas políticas e, sobretudo, para garantir as pequenas conquistas legais obtidas por meio de muitas negociações, que, no entanto, são constantemente ameaçadas pela força do poder político conservador no País. Em seu texto, ressalta a vocação política do feminismo brasileiro para a negociação e para os alcances diferenciados do movimento, em função dessa cultura, mais centrado no nível político e menos na interlocução com a sociedade. Sua análise é bastante provocativa para o movimento feminista, já que sugere um aprofundamento da interlocução com a sociedade civil, o que nos parece fundamental, sobretudo, porque, como sabemos, o aborto é uma possibilidade com a qual a maioria das mulheres de diferentes classes e condições sociais se defronta em algum momento de suas vidas, apesar de que, no nível da regra, ${ }^{13}$ o apelo do discurso pró-vida ainda se mantém.

Aliás, o que chamamos de interrupção da gravidez e de aborto são práticas cujos significados têm variado muito, conforme os contextos etnográficos e os períodos históricos, como têm mostrado várias estudiosas no campo da História e da Antropologia, particularmente. Neste sentido, temos o artigo da antropóloga Flávia Motta, que nos mostra o quanto o que chamamos de aborto provocado faz parte do repertório de experiências de

\footnotetext{
${ }^{13}$ Segundo a sugestão de Ondina Leal e Bernardo Lewgoy (1995), a partir de um contexto etnográfico específico, coexistem dois modelos (duas ontologias) - um substancialista, situado no nível da regra, e outro relacional/holista, situado no nível da prática - que fazem com que as mesmas pessoas que são contra o aborto "em geral" recorram a ele em situações específicas.
} 
mulheres de classes populares e o quanto denota sua capacidade de agenciamento diante de uma possível gravidez. Com sua pesquisa, pretendeu fazer uma história etnográfica do aborto provocado entre mulheres de classes populares no século XX, no Rio Grande do Sul e em Santa Catarina, tentando compreendê-lo, nos relatos das mulheres entrevistadas, como manifestação de uma outra lógica simbólica. Ao apresentar algumas referências às práticas cotidianas de mulheres de camadas populares e aos saberes conflitantes que as envolvem, a antropóloga traz as falas das mulheres que entrevistou, relatando suas concepções a respeito da vida e do próprio corpo nas experiências vivenciadas do "fazer vir" e "fazer descer". Como analisam outras estudiosas do tema com quem a autora estabelece sua interlocução, tais concepções são bastante diversas das noções evocadas nos púlpitos e nos consultórios que ressaltam que o que estaria em questão num aborto seria a vida de uma pessoa dotada de atributos individuais, conceitos eivados de valores modernos, os quais não são necessariamente compartilhados por todas as pessoas em todos os lugares.

Enquanto preparávamos este dossiê e nos perguntávamos sobre qual seria o título mais adequado para ele, seguia no Congresso Nacional brasileiro a votação do Projeto de Lei PL1 135/1991, que suprimiria o artigo 124 do Código Penal brasileiro, o qual caracteriza como crime o aborto provocado. Infelizmente, na votação em Plenária, essa proposta foi rechaçada. No Brasil, como em outros países, a luta pela descriminalização do aborto, literalmente, continua.

Cabe destacar que, infelizmente, neste momento não apresentamos artigos acerca de realidades sociais de países que já descriminalizaram o aborto, como é o caso de Cuba, que, desde 1965, permite o aborto em qualquer situação por livre demanda da mulher, e também não apresentamos material referente ao mundo árabe, à Ásia e à África. No entanto, acreditamos que os artigos selecionados para este dossiê contribuirão para $O$ refinamento do debate, numa perspectiva feminista e comprometida, e enfrentarão o grande desafio de aprofundar a interlocução dos estudos feministas com a sociedade civil.

\section{Referências bibliográficas}

A MARGEM do corpo. Direção de Débora Diniz. Brasília: Anis, 2004. 1 cassete, VHS-NTSC, son., color.

ARDAILLON, Danièlle. "O lugar do íntimo na cidadania de corpo inteiro". Revista Estudos Feministas, Rio de Janeiro, IFCS/UFRJ, v. 5, n. 2, p. 376-388, 1997.

BARSTED, Leila Linhares. "O movimento feminista e a descriminalização do aborto". Revista Estudos Feministas, Rio de Janeiro, IFCS/UFRJ, v. 5, n. 2, p. 397-403, 1997.

. "Legalização e descriminalização do aborto no Brasil: 10 anos de luta feminista". Revista Estudos Feministas, Rio de Janeiro, IFCS/UFRJ, v. 0, n. 1, p. 104-130, 1992.

CENTER FOR REPRODUCTIVE RIGHTS. 2007. Disponível em: www.reprorights.org. Acesso em: 14 jun. 2008.

HISTÓRIA de uma vida severina. Direção de Débora Diniz. Brasília: Anis, 2005. 1 cassete, VHSNTSC, son., color.

LEAL, Ondina; LEWGOY, Bernardo Pessoa. "Aborto e contracepção". In: LEAL, Ondina (Org.). Corpo e significado: ensaios de antropologia social. Porto Alegre: UFRGS, 1995. p. 57-76. MOTTA, Flávia. "Sonoro silêncio: por uma história etnográfica do aborto". Revista Estudos Feministas, v. 16, n. 2, p 681-689. Florianópolis, 2008.

PORTO, Rozeli. "Objeção de consciência, aborto e religiosidade: práticas e comportamentos dos profissionais de saúde em Lisboa". Revista Estudos Feministas, v. 16, n. 2, p 661-666, Florianópolis, 2008. 
REVISTA ESTUDOS FEMINISTAS. Rio de Janeiro, CIEC/UERJ, v. 1, n. 2, 1993.

REVISTA ESTUDOS FEMINISTAS. Florianópolis, CFH/CCE/UFSC, v. 8, n. 1, 2000.

ROSTAGNOL, Susana. "El conflicto mujer-embrión en debate parlamentario sobre el aborto". Revista Estudos Feministas, v. 16, n. 2, p 667-674, Florianópolis, 2008. 